\title{
Effectiveness of Buteyko Breathing Technique versus Nadi Shuddhi Pranayama to Improve Pulmonary Function in Subjects with Bronchial Asthma
}

\author{
G Swathi ${ }^{1}$, T Sunil Kumar ${ }^{1}$, N Raghunadh ${ }^{2}$, Ch Marry Margrett ${ }^{3}$ \\ ${ }^{1}$ Associate Professor, ${ }^{2}$ Professor, ${ }^{3}$ Assistant Professor, \\ Department of Physiotherapy, Konaseema Institute of Medical Science, Amalapuram, India
}

Corresponding Author: G Swathi

\begin{abstract}
Background: Asthma is a chronic lifethreatening disease as the airways in the lungs often swollen or inflamed, which makes the airways very sensitive. So, the exposure to the environment in day-to-day life triggers asthma. Asthma can affect at any age group. This study mainly focuses on comparing the effects of Buteyko breathing technique and Pranayama on improving Pulmonary Function in subjects with Bronchial Asthma.

Method: Total of 79subjects selected, out of those 66 subjects were included after obtaining the consent document. Subjects are divided into two groups by lottery method, in which 6 subjects dropped. So, the study was completed with 60 subjects. Both groups performed intervention for 1 hour a day 5 days week for 4 weeks. The outcomes of the study were FEV1, FVC \& FEV1/FVC ratio.

Results: Paired $t$ test was used to assess statically significance between pre and post test scores within the groups, independent $t$ test was used to access statistical significance of post-test mean score between the groups, statistical analysis of the data revealed that Buteyko Breathing technique group has more difference when compare to Pranayama group.
\end{abstract}

Conclusion: The results had shown that both Group-A (Buteyko Breathing Group) and Group-B (Pranayama Group) has improved significantly on pre and post-test values within the groups but when compared between the groups statistical significance is noted in GroupA. So, this study concludes that Group-A showed significant improvement on Pulmonary Function in subjects with Bronchial Asthma.

Keywords: Buteyko Breathing technique, Nadi Shuddhi Pranayama, FEV1/FVC, Bronchial Asthma.

\section{INTRODUCTION}

Asthma is a heterogeneous disease, usually characterized by chronic airway inflammation. It is defined by the history of respiratory symptoms that vary over time and in intensity, together with variable expiratory airflow limitation (GINA 2015).

Asthma can affect people of any age, but often starts in childhood. Prevalence of asthma globally has estimated about $1 \%$ to 18\% (300 million individuals) and in India has estimated about $2.05 \%$ to $3.5 \%$ (17-30 million individuals) of all age groups. Asthma is a rare cause of mortality, contributing to less than $1 \%$ of all deaths in most countries worldwide. The annual death rate of asthma in India is 250,000 . Rates of death rise almost exponentially from midchildhood to old age, so the majority of asthma deaths occur after middle age in low- and middle-income groups. ${ }^{1,2}$

Asthma is classified into two types, atopic and non-atopic. Atopic or Allergic asthma is most easily recognised asthma phenotype often commences in childhood and is associated with past and/or family history of allergic disease such as eczema, 
allergic rhinitis/food/drug allergy. NonAtopic or Non-Allergic asthma occurs in adults that is not associated with allergy. ${ }^{3}$

Symptoms include wheeze, shortness of breath, chest tightness or cough and variable expiratory airflow limitation which often worse at night or in the early morning that vary over time and in intensity. The typical wheeze found in asthmatics is a continuous, polyphonic whistling sound produced in the airways' during expiration is due to obstruction of the airways on breathing out. The obstruction of the airways decreases the rate at which air can flow. This is felt as tightness in the chest and shortness of breath. The obstruction and inflammation cause coughing affecting the pulmonary function in asthmatics. ${ }^{3}$

The causes of asthma are not well understood. A number of risk factors are associated with the condition, often in combination which can be genetic and/or environmental ${ }^{3}$. These variants are often triggered by factors such as exercise, allergens/irritant exposure, change in weather, or viral respiratory infections. ${ }^{3}$

Asthma is diagnosed by identifying the characteristic pattern of respiratory symptoms and variable expiratory airflow limitation. $^{3}$

Conservative treatment for bronchial asthma includes pharmacological and physical therapy. Pharmacological treatment includes Inhaled Corticosteroids (ICS) and Bronchodilators like Short-acting beta $2^{-}$ agonist (SABA) and Long-acting beta $2^{-}$ agonist $(\mathrm{LABA})^{3}$. Pharmacological therapies have been shown to reduce symptoms, improve lung function and prevent exacerbations, with an acceptable safety profile. Physical therapy treatment for bronchial asthma is given to prevent chronic symptoms, to reduce frequent use of SABA, to maintain normal pulmonary function, to prevent exacerbations, minimize the need of emergency care, hospitalization, prevent loss of lung function and to prevent adverse effects of therapy by breathing exercises, chest percussion, postural drainage, active cycle of breathing technique and chest mobility exercises. ${ }^{4-7}$

Breathing techniques along with pharmacological treatment showed better results in reducing asthma symptoms and improving the pulmonary function ${ }^{8}$. Several studies found out of that both breathing techniques like Buteyko breathing technique and pranayama like Nadi shuddhi were found to be effective to treat bronchial asthma.

Buteyko breathing method was named after it's originator Dr. Konstantin Pavlovich Buteyko which lies on the fundamental principle of the carbon dioxide theory, a unique breathing therapy that uses breath control and breath holding exercises which are used to correct hyperventilation and low carbon dioxide level ${ }^{9,10}$.

Pranayama is a type of breathing technique in Yoga. There are different methods of practicing pranayama. Some are on slow and soft rhythm and some are on fast and forceful rhythm that increases the depth of breathing. Nadi shuddhi pranayama is a slow and soft rhythm pranayama that increases the respiratory stamina, relaxes the chest muscles, expands the lungs, and raises energy levels, calms the body and causes over-all improvement in lung functions. ${ }^{11,12}$

Spirometer is a non-invasive diagnostic instrument for screening and basic testing of $\mathrm{FEV}_{1}, \mathrm{FVC}$ and $\mathrm{FEV}_{1} / \mathrm{FVC}$ major outcomes tested in pulmonary function to assess reversible airway obstruction. It is valid, reliable and can be performed fast at fairly low cost. It emphasizes to detect airflow limitation and total lung capacity providing visual feedback.

To decrease this hyperventilation breathing techniques have been employed. Both the techniques like Buteyko breathing technique and pranayama have been proved to be effective to maintain normal pulmonary function, to decrease exacerbations, and to improve normal breathing pattern. There are very few studies comparing these two techniques on pulmonary function showing long term 
effects in which results are consistent but short-term effects were not known. So, scarcity on these techniques urged me to conduct this study comparing the short-term effects of Buteyko breathing technique versus pranayama on pulmonary function in asthmatic patients.

\section{MATERIALS AND METHODS}

Study Setting: Department of Pulmonology, KIMS General Hospital, Amalapuram.

Study Design: Experimental design.

Study Type: Randomized Control Trail.

Study Sampling: Simple Random Sampling.

Method of Data Collection: Total of 79 subjects were selected, out of those 66 subjects were included who met the inclusion criteria and willing to participate in the study after obtaining the consent form were included. These 66 subjects are randomized into two groups by simple random sampling, selected by lottery method and divided into Experimental Group-A and Experimental Group-B. In which 6 subjects dropped from the study due to change in the medication. The study was completed with the sample of 60 subjects

\section{Sampling Size: 60}

Group-A: 30 patients are assigned to this group and were trained Buteyko breathing technique.

Group-B: 30 patients are assigned to this group and were trained pranayama.

Study Duration: 1 year

Treatment Duration: 5 days a week for 4 Weeks.

Recording Materials: Spirometer, Assessment Performa, Data collection chart

\section{Inclusion Criteria}

- Diagnosed as bronchial asthma by the physician.

- Age group between 20-60 years of both genders.

- Symptoms $>2$ days/week but not daily.

- Night time awakening 3-4x/month.

- Lung function.
$>\operatorname{FEV} 1(\%$ predicted $)---<80 \%$

$>\mathrm{FEV}_{1} / \mathrm{FVC}$ Ratio --- $<75 \%$

\section{Exclusion Criteria}

- Change in the inhaled steroid or used oral steroids during the 4-week run in period.

- Mental disorders.

- Malignancies.

- Musculoskeletal, rheumatic, cardiac /neurological disorders.

\section{Outcome Measures}

- $\mathrm{FEV}_{1}$

- FVC

- $\mathrm{FEV}_{1} / \mathrm{FVC}$

\section{PROCEDURE}

Patients who were clinically diagnosed with Bronchial Asthma were treated in the in-patient basis. During the training program all the patients are allowed to continue the pharmacological therapy. A total of 60 subjects who met the inclusion are explained about the condition and mode of assessment, and a written informed consent is obtained from them. Subjects were divided into 2 groups, GROUP-A and GROUP-B by simple randomization. Subjects in GROUP-A are treated with Buteyko Breathing technique along with conventional chest physiotherapy and subjects in GROUP-B are treated with Pranayama along with conventional physiotherapy for 5 days a week.

Initial evaluation of FEV1, FVC and FEV1/FVC values are taken by using a portable electronic spirometer. Initially name, age, height and weight of the patient were entered in to the data of the machine in order to get percentage predicted values.

\section{GROUP-A (BUTEYKO BREATHING):}

The subjects assigned to this group received the designed Buteyko Breathing Technique and were on medical treatment.

Each patient was trained by Buteyko Breathing Technique 5 times a week for 20 minutes in a session for 4 weeks.

The time of the session was in the morning at least two hours after meals. Each 
patient performed the technique by himself at home twice daily (in the morning and in the evening, at least two hours after the meals) during the time of the study. The Buteyko technique involves periods of breath holding, known as 'control-pause' and interspersed with periods of 'shallow breathing or maximum pause'.

Steps in Buteyko Technique:

- Step 1: The "Control pause" breathing test

$>$ The patient is asked to sit in an upright and relaxed position, by relaxing the shoulders and resting the back against the chair.

$>$ Patient is asked to take the normal breath without any change before taking control pause. Now the patient is asked to take a small breath in (2s) and a small breath out $(3 \mathrm{~s})$. Hold the nose on the "out" breath, with empty lungs but not too empty. Holding the nose is necessary to prevent the air entering into the airways.

$>$ The patient is asked to count how many seconds that he or she can comfortably last by holding the nose before he or she needs to breathe in again. The patient is asked to hold the breath until he or she feels the first need to breathe in, then is asked to release the nose and breathe in.

$>$ The control pause should not be more than 30secs, this may lead to take a deep breath.

- Step 2: Shallow breathing or Maximum pause

$>$ The patient is asked to monitor the amount of air flowing through his or her nostrils by placing the finger under the nose in a horizontal position. The finger should lie just above the top lip close to the nostrils. 2 to 3 flickers of air (may be $1 \mathrm{~cm}$ with each breath) is taken in.

$>$ Now exhale as slowly as possible on the finger placed close to the nostrils. Feel the warm air while breathing out. Concentrate on calming the breath to reduce the amount of warm air that is felt on the finger. As there is reduction in the warm air, he or she will begin to feel a need or want of air. Then the patient is asked to try to maintain the need for air as much as he or she can (this in most is double the control pause).

- Step 3: Putting step 1 and step 2 together:

Take a control pause followed by shallow breathing or maximum pause and wait for 2 mins. This is repeated as many times as a patient can perform in 20 minutes.

\section{GROUP-B (PRANAYAMA)}

The subjects assigned to this group received the Nadishuddhi Pranayama Technique and were on medical treatment for 4 weeks.

Each patient was trained by Nadi shuddhi Pranayama Technique 5 times a week for 20 minutes in a session.

The time of the session was in the morning at least two hours after meals.

Each patient performed the technique by himself at home twice daily (in the morning and in the evening, at least two hours after the meals) during the time of the study.

The patients were asked to assume 'Sukhasana' (the comfortable posture) and regulate the alteration of breathing as follows:

1. Open the right hand and bend index and middle fingers against the palm. The thumb was used for closing the right nostril while the fourth and fifth fingers were used for the left nostril.

2. Place the right thumb against the ala at the end of the nostril to close it and similarly press the fourth and fifth fingertips against the left nostril.

3. Start the exercise in the 'Sukhasana posture', with relaxed attitude and concentration as below.

- Exhale slowly and deeply without closing the nostrils but being ready to do.

- Inhale slowly and quietly through the left nostril while closing the right. 
- At the end of the inhalation, close both nostrils and hold the breath for a while (not more than 1-2 seconds).

- Keep the left nostril closed and exhale through the right as quietly as possible.

- After exhaling completely, inhale slowly and quietly through the right nostril.

- Close both nostril and wait for a while, then open the left nostril and exhale slowly and silently.

- Inhale through the same nostril and continue.

- This is repeated as many times as a subject can perform in 20 minutes.

\section{CONVENTIONAL PHYSIOTHERAPY} Airway Clearance Techniques

Percussion: Percussion involves rhythmically striking the chest wall with cupped hands of the therapist over the involved lung area. It is also called cupping or clapping. The purpose of percussion is to break up thick secretions in the lungs so they can more easily be removed. Percussion is performed on each lung segment for one to two minutes at a time.

Vibration: As with percussion, the purpose of vibration is to help break up lung secretions. While performing the vibration therapist places his or her hands against the patient's chest and creates vibrations by quickly contracting and relaxing arm and shoulder muscles while the patient exhales.

Postural drainage: Postural drainage uses the force of gravity to assist in effectively draining secretions from the smaller airways into the central airway where they can either be coughed up or suctioned out. To obtain the head-down positions, the use of a pillow, beanbag chair, or couch cushions can be helpful. Often, percussion and vibration are performed in conjunction with postural drainage.

Coughing: Coughing helps to break up secretions in the lungs so that the mucus can be expectorated or suctioned out if necessary. Patients sit upright and inhale deeply through the nose. The abdomen is contracted, and then exhales in short huffs or coughs.

Active cycle of breathing techniques (ACBT): ACBT is a forced expiratory technique that has been shown to increase the efficiency in the clearance of bronchial secretions, without causing or increasing bronchospasm. It consists of breath control, thoracic expansion and forced expiratory techniques like coughing or huffing.

\section{Breathing techniques and positioning}

Diaphragmatic breathing: The diaphragm is the most efficient muscle of breathing. It is a large, dome-shaped muscle located at the base of the lungs. Lie on your back on a flat surface or in bed or sit with relaxed shoulders, head and neck. Place one hand on the chest and other just below the rib cage, breathe in slowly through the nose so that stomach moves out against the hand. The hand on the chest should remain as still as possible. Tighten the stomach muscles, letting them fall inward as exhaling through pursed lips. Diaphragmatic breathing helps to strengthen the diaphragm, decrease the work of breathing by slowing your breathing rate, decrease oxygen demand, useless effort and energy to breathe.

\section{DIAPHRAGMATIC BREATHING}

Pursed-Lip Breathing: Pursed-lip breathing is the chief form of breathing control advocated for asthmatics. Pursed-lip breathing is designed to control shortness of breath by slowing the pace of breathing and increasing the effectiveness of each breath. This is performed by inhaling through the nose and then exhaling through partially closed lips (as during whistling). Pursed-lip breathing acts as a "splint." It creates a back pressure that helps keep the airways open slightly longer to allow more stale air to escape so that more fresh air can replace it.

The positions most commonly used are:

$>$ Half lying

$>$ Side lying with the upper arm supported on a pillow 
$>$ High side lying with the arm supported on a pillow

$>$ Sitting in a comfortable upright chair

\section{Statistical Method}

Statistical analysis of the present study was done by using SPSS software version 20.0 and manually. Student $t$ test (independent) were used to find out the significance in between groups and student $t$ test (paired) were used to find out the significance within the group.

\section{RESULTS}

The results of this study were analysed in terms of increased pulmonary function on Spirometry values.
Comparison was done both within each group as well as in between the two groups. So as to evaluate the intra group and inter group effectiveness of Buteyko breathing technique and Pranayama which are under considerations in the present study.

Group-A (Buteyko Breathing Group) and Group-B (Pranayama Group) who received four weeks of therapy has improved significantly on pre and post-test values within the groups but when compared between these groups statistical significance is noted in Group-A (Buteyko Breathing Group).

Table 1: Analysis of Spirometry values on pulmonary function in Group-A (Buteyko group) with pre and post interventions

\begin{tabular}{|c|c|c|c|c|c|c|}
\hline PARAMETERS & $\mathbf{N}$ & MEAN & $\begin{array}{l}\text { Standard } \\
\text { Deviation }\end{array}$ & t-value & D f & p-value \\
\hline $\mathrm{FEV}_{1}$ (pre) & 30 & 1.81 & 0.089 & \multirow[t]{2}{*}{-3.1569} & \multirow[t]{2}{*}{29} & \multirow[t]{2}{*}{0.03} \\
\hline $\mathrm{FEV}_{1}$ (post) & 30 & 1.861 & 0.091 & & & \\
\hline FVC (pre) & 30 & 1.819 & 0.094 & \multirow[t]{2}{*}{-3.5697} & \multirow[t]{2}{*}{29} & \multirow[t]{2}{*}{0.04} \\
\hline FVC (post) & 30 & 1.913 & 0.097 & & & \\
\hline $\mathrm{FEV}_{1} / \mathrm{FVC} \%$ (pre) & 30 & 70.94 & 3.163 & \multirow[t]{2}{*}{2.01359} & \multirow[t]{2}{*}{29} & \multirow[t]{2}{*}{0.03} \\
\hline $\mathrm{FEV}_{1} / \mathrm{FVC} \%$ (post) & 30 & 74.066 & 3.222 & & & \\
\hline
\end{tabular}

Improvement in pulmonary function was recognized by increase in Spirometry values. For these Spirometry values of $\mathrm{FEV}_{1}, \mathrm{FVC}$ and $\mathrm{FEV}_{1} / \mathrm{FVC} \%$ were noted on the first day and the last day (after 4 weeks) of the treatment for all the subjects. However, the difference between the scores were considered for analysis of difference between the pre and post-test values in Group-A.

Table 2: Analysis of in Spirometry values on pulmonary function in Group-B (Pranayama group) with pre and post intervention

\begin{tabular}{|c|c|c|c|c|c|c|}
\hline PARAMETERS & $\mathbf{N}$ & MEAN & $\begin{array}{l}\text { Standard } \\
\text { Deviation }\end{array}$ & t-value & D f & p-value \\
\hline $\mathrm{FEV}_{1}$ (pre) & 30 & 1.833 & 0.087 & \multirow[t]{2}{*}{-3.90408} & \multirow[t]{2}{*}{29} & \multirow[t]{2}{*}{0.05} \\
\hline $\mathrm{FEV}_{1}$ (post) & 30 & 1.857 & 0.089 & & & \\
\hline FVC (pre) & 30 & 1.815 & 0.0913 & \multirow[t]{2}{*}{-2.21901} & \multirow[t]{2}{*}{29} & \multirow[t]{2}{*}{0.04} \\
\hline FVC (post) & 30 & 1.837 & 0.093 & & & \\
\hline $\mathrm{FEV}_{1} / \mathrm{FVC} \%$ (pre) & 30 & 69.8 & 3.1540 & \multirow[t]{2}{*}{-3.41077} & \multirow[t]{2}{*}{29} & \multirow[t]{2}{*}{0.05} \\
\hline $\mathrm{FEV}_{1} / \mathrm{FVC} \%$ (post) & 30 & 70.7066 & 3.192 & & & \\
\hline
\end{tabular}

Improvement in pulmonary function was recognized by increase in Spirometry values. For these Spirometry values of $\mathrm{FEV}_{1}, \mathrm{FVC}$ and $\mathrm{FEV}_{1} / \mathrm{FVC} \%$ were noted on the first day and the last day (after 4 weeks) of the treatment for all the subjects. However, the differences between the scores were considered for analysis of difference between the pre and post-test values in Group-B.

Table 3: Analysis of in Spirometry values on pulmonary function in between the groups (Group-A \& Group-B) with post interventions

\begin{tabular}{|c|c|c|c|c|c|c|c|}
\hline PARAMETERS & $\mathbf{N}$ & MEAN & $\begin{array}{l}\text { Standard } \\
\text { Deviation }\end{array}$ & t-value & D f & p-value & Inference \\
\hline $\mathrm{FEV}_{1}$ (Group-A post) & 30 & 1.37 & 0.0961 & \multirow[b]{2}{*}{4.1664} & \multirow[b]{2}{*}{53} & \multirow[b]{2}{*}{0.05} & \multirow[t]{2}{*}{ significant } \\
\hline $\mathrm{FEV}_{1}$ (Group-B post) & 30 & 1.359 & 0.0696 & & & & \\
\hline FVC(Group-A post) & 30 & 1.861 & 0.093 & \multirow[b]{2}{*}{2.0135} & \multirow[b]{2}{*}{58} & \multirow[b]{2}{*}{0.04} & \multirow[t]{2}{*}{ significant } \\
\hline FVC(Group-B post) & 30 & 1.8233 & 0.0918 & & & & \\
\hline $\mathrm{FEV}_{1} / \mathrm{FVC} \%$ (Group-A post) & 30 & 74.0666 & 3.2221 & \multirow[b]{2}{*}{4.0576} & \multirow[b]{2}{*}{58} & \multirow[b]{2}{*}{0.05} & \multirow[t]{2}{*}{ significant } \\
\hline $\mathrm{FEV}_{1} / \mathrm{FVC} \%$ (Group-B post) & 30 & 71.7066 & 3.192 & & & & \\
\hline
\end{tabular}


G Swathi et.al. Effectiveness of Buteyko breathing technique versus Nadi shuddhi Pranayama to improve pulmonary function in subjects with Bronchial Asthma

Improvement in pulmonary function was recognized by increase in Spirometry values. For these Spirometry values of $\mathrm{FEV}_{1}, \mathrm{FVC}$ and $\mathrm{FEV}_{1} / \mathrm{FVC} \%$ were noted on the first day and the last day (after 4 weeks) of the treatment for all the subjects. However, the differences between the scores were considered for analysis of difference between the Group-A \& Group-B.

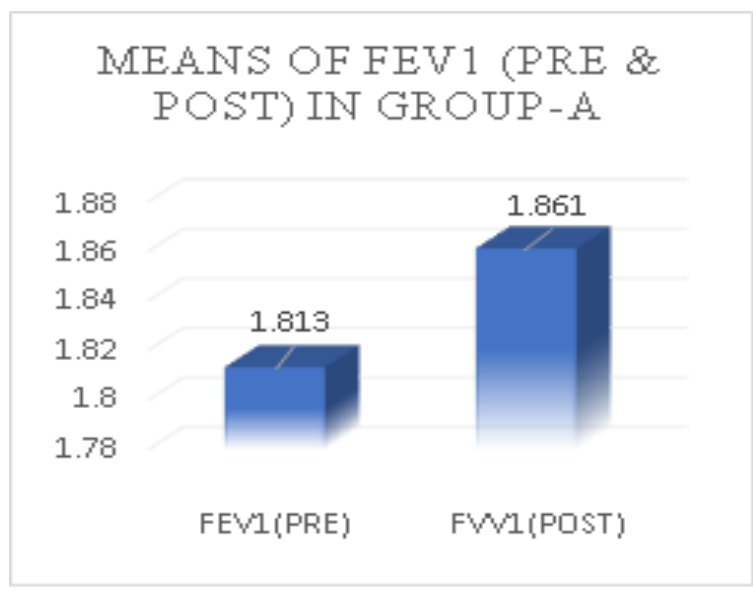

Graph 1: Analysis of $\mathrm{FEV}_{1}$ values on pulmonary function in Group-A (Buteyko group) with pre and post interventions

MEANS OF FVC (PRE \& POST) IN GROUP -A

$$
1.95
$$$$
1.9
$$$$
1.85
$$$$
1.8
$$$$
1.75
$$$$
1.913
$$

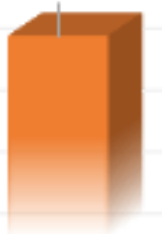

FVC (PRE) FVC(POST)

Graph 2: Analysis of FVC values on pulmonary function in Group-A (Buteyko group) with pre and post interventions

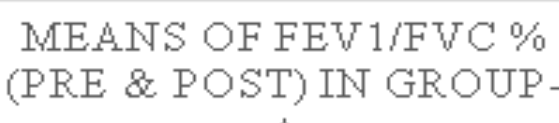
A

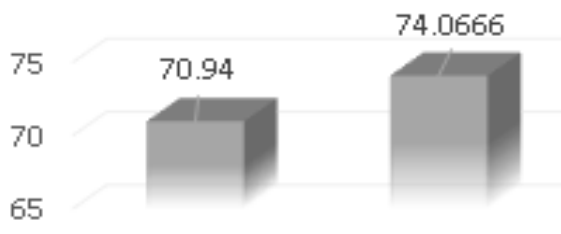

FEV1/FVC\% (PRE) FEV1/FVC\& (POST)

Graph 3: Analysis of $F E V_{1} / F V C$ values on pulmonary function in Group-A (Buteyko group) with pre and post interventions
There was significant difference between the Spirometry values $\mathrm{FEV}_{1}$ $(\mathrm{p}<0.03)$, FVC $(\mathrm{p}<0.04)$ and $\mathrm{FEV}_{1} / \mathrm{FVC} \%$ $(\mathrm{p}<0.03)$ noted in the subjects in Group-A.

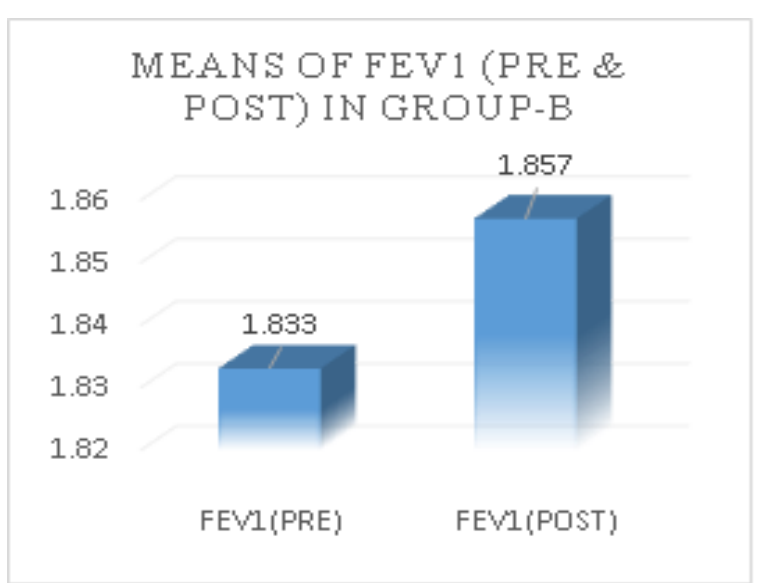

Graph 4: Analysis of in $\mathrm{FEV}_{1}$ values on pulmonary function in Group-B (Pranayama group) with pre and post intervention

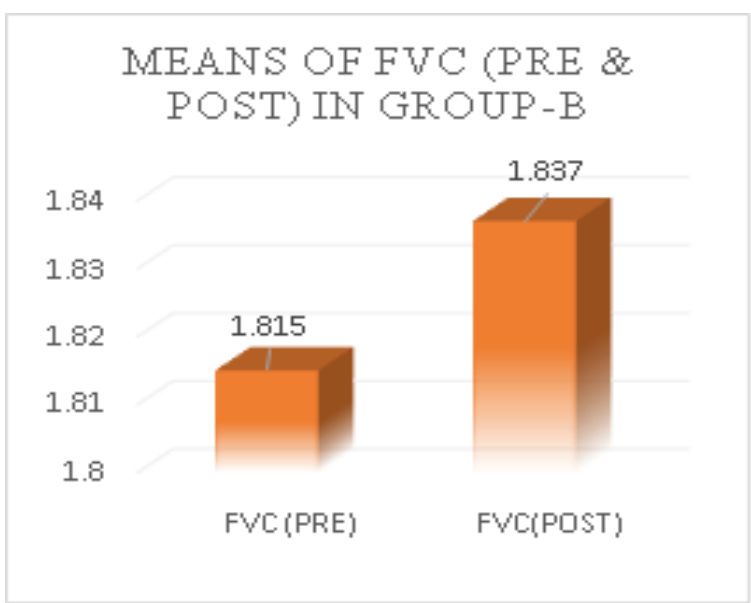

Graph 5: Analysis of in FVC values on pulmonary function in Group-B (Pranayama group) with pre and post intervention

\section{MEANS OF FEV $1 /$ FVC \%}

(PRE \&POST) IN GROUP-B

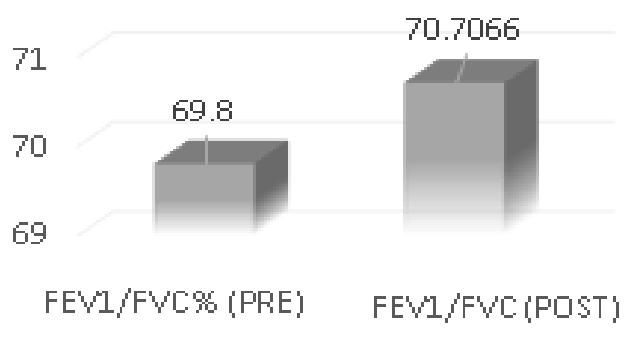

Graph 6: Analysis of in $\mathrm{FEV}_{1} / \mathrm{FVC}$ values on pulmonary function in Group-B (Pranayama group) with pre and post intervention

There was significant difference between the Spirometry values $\mathrm{FEV}_{1}$ 
$(\mathrm{p}<0.05)$, FVC $(\mathrm{p}<0.04)$ and $\mathrm{FEV}_{1} / \mathrm{FVC} \%$ $(\mathrm{p}<0.05)$ noted in the subjects in Group-B.

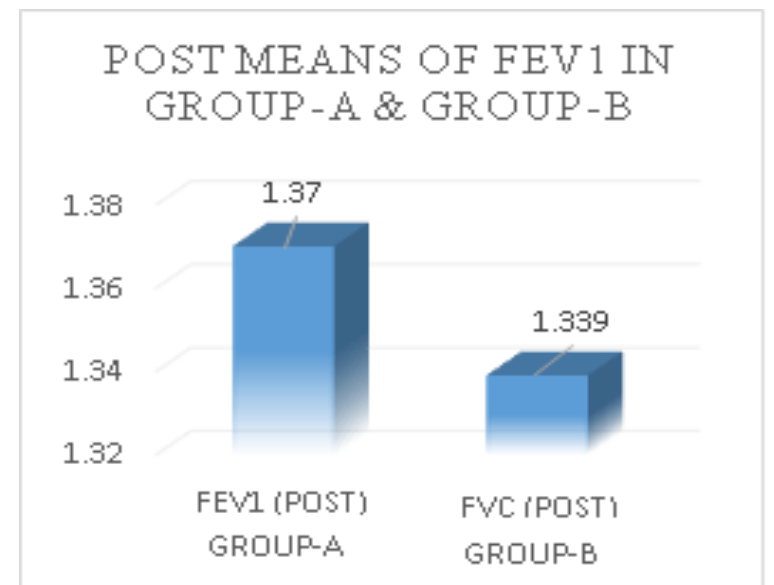

Graph 7: Analysis of in $\mathrm{FEV}_{1}$ values on pulmonary function in between the groups (Group-A \& Group-B) with post interventions

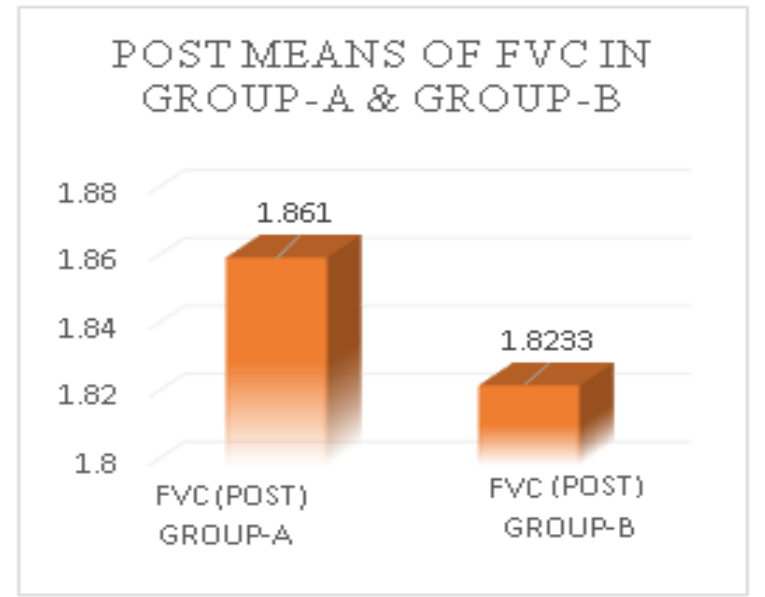

Graph 8: Analysis of in FVC values on pulmonary function in between the groups (Group-A \& Group-B) with post interventions

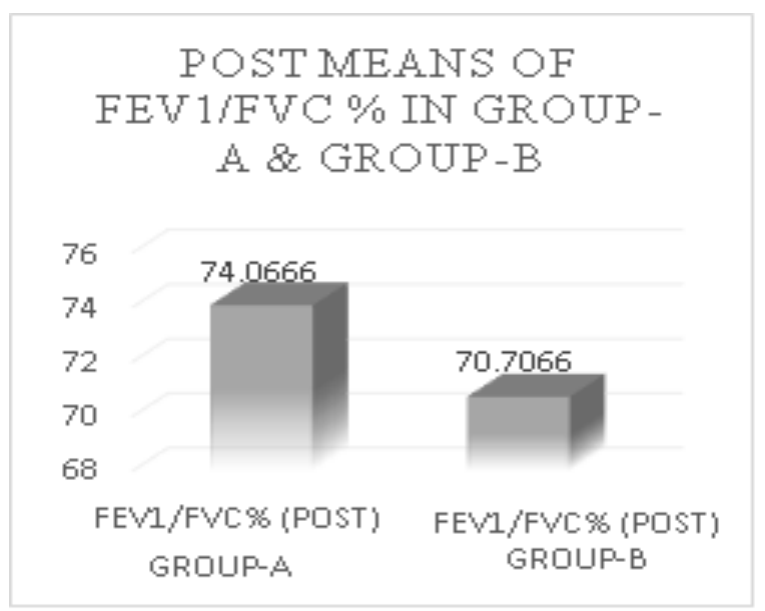

Graph 9: Analysis of in $\mathrm{FEV}_{1} / \mathrm{FVC}$ values on pulmonary function in between the groups (Group-A \& Group-B) with post interventions
There was significant difference between the Spirometry values of $\mathrm{FEV}_{1}$ $(\mathrm{p}<0.05)$, FVC $(\mathrm{p}<0.04)$ and $\mathrm{FEV}_{1} / \mathrm{FVC} \%$ $(\mathrm{p}<0.05)$ noted in between the groups.

\section{DISCUSSION}

The study results demonstrated better trends of improvement in the Buteyko group on pulmonary function than in Pranayama group. Both the breathing training groups showed significant improvement in pulmonary function compared to the baseline values but when compared between these groups, Buteyko method showed statistically significant improvement when compared to Nadi shuddhi Pranayama method.

Patients with asthma may demonstrate wheeze, chest tightness or cough and variable expiratory airflow limitation even at rest limiting the activity due to intense dyspnea sensations that show effect on pulmonary function. Due to these symptoms and alterations in expiratory flow it is difficult for asthma patients in performing activities of daily living which urged me to conduct this study on asthma subjects, whose recovery can be prudent for their family and their social life.

"However, regular breathing exercises have been associated with reduced risk of hospitalization for asthma and mortality among patients with asthma."

The results of the study showed a statistically significant improvement in $\mathrm{FEV}_{1} \quad(\mathrm{p}<0.03), \quad \mathrm{FVC} \quad(\mathrm{p}<0.04) \quad$ and $\mathrm{FEV}_{1} / \mathrm{FVC} \%(\mathrm{p}<0.03)$ in pre and post-test values who received four weeks of therapy within the Buteyko group.

The improvement of pulmonary function in the Buteyko group could be a result of improvement in 'hidden hyperventilation' as claimed by Buteyko. There is evidence of hyperventilation causing decreased $\mathrm{CO}_{2}$ levels, resulting in asthma symptoms and also linked to poor pulmonary function. ${ }^{32}$

Most of the Chronic Obstructive Pulmonary Disease research has elaborated the significance of pulmonary function in 
asthmatics is due to dysfunctional breathing. The reasons for the improvement in mean of pre and post-test values may be due to Buteyko Breathing Technique which uses breath control and breath-holding exercises. The fundamental principle of the Buteyko theory is that chronic hyperventilation causes a loss of carbon dioxide $\left(\mathrm{CO}_{2}\right)$ in the lungs and in the blood. A deficit of $\mathrm{CO}_{2}$ disturbs the body's acid-alkaline balance, causing bronchoconstriction, constriction of blood vessels and smooth muscle, and poor tissue oxygenation. This is related to the Bohr effect i.e.; haemoglobin's oxygen binding affinity is inversely related both to acidity and to the concentration of $\mathrm{CO}_{2}$. Professor Buteyko stated that reducing breathing volume by using breath-holding techniques raised $\mathrm{CO}_{2}$ levels and reversed bronchoconstriction by improving in pulmonary function. ${ }^{10,27,28}$

Other beneficial effects of Buteyko Breathing Technique decreased the number and severity of attacks as well as the dosage of medication, improved quality of life, minimized the need of emergency care and hospitalization. ${ }^{10}$

Group which received Buteyko breathing technique had a significant change in $\mathrm{FEV}_{1}, \mathrm{FVC}$ and $\mathrm{FEV}_{1} / \mathrm{FVC}$ \%with a $\mathrm{p}$ value of $0.03,0.04$ and 0.03 and the result of this study is similar to the study conducted by Zahra Mohamed Hassan et al (2012) who concluded that Buteyko breathing technique is effective in improving pulmonary function and significant decrease in asthma daily symptoms. ${ }^{4}$

The results of the study showed a statistically significant improvement in $\mathrm{FEV}_{1} \quad(\mathrm{p}<0.05), \quad$ FVC $\quad(\mathrm{p}<0.04)$ and $\mathrm{FEV}_{1} / \mathrm{FVC} \%(\mathrm{p}<0.05)$ in pre- and post- test of values within the Pranayama group who received four weeks of therapy.

Several studies have proved Pranayama to be helpful in the treatment of asthma by increasing the depth of breathing. The reasons for the improvement in mean of pre and post-test values may be due to alternate nostril breathing in nadi shuddi pranayama by increasing the depth of breathing. Lungs expand considerably and walls of the alveoli are stretched to maximum. Then it stimulates the stretch receptors situated in the alveolar walls. Chest continues to expand under cortisol control. By doing so, it increases the surface area and air diffusion across the alveoli membrane. Exchange of $\mathrm{O}_{2}$ and $\mathrm{CO}_{2}$ across the thin wall of the alveoli and blood capillaries takes place more as they practice more time. As the expiratory reserve volume of the air is used the air containing $\mathrm{CO} 2$ is squeezed out from the lungs. Dysfunctional breathing in asthma reduces the response of chemoreflex to hypercapnia and hypoxia. The baro reflexes sensitivity is also high compared to the normal breathing. It stimulates the theta amplitude and delta waves, which is an indication to the parasympathetic state arousal. Pranayama activates the pulmonary stretch receptors and which induce the duration \& frequency of inhibitory neural impulses. Lung inflation is a main physiological stimulus to release lung surfactant and prostaglandins into alveolar space and it reduces the tone of bronchial smooth muscle. ${ }^{36}$

Group which received Nadi shuddhi pranayama had a significant change in $\mathrm{FEV}_{1}, \mathrm{FVC}$ and $\mathrm{FEV}_{1} / \mathrm{FVC} \%$ with a $\mathrm{p}$ value of $0.04,0.05$ and 0.04 and the result of this study is similar to the study conducted by Savita Singh et al (2011) who concluded that Nadi shuddhi pranayama is effective in improving pulmonary function, transfer factor of lung for carbon monoxide and significant decrease in asthma daily symptoms. $^{22}$

The present study was conducted with breathing techniques along with conventional chest physiotherapy, to understand its short-term effects on patients with asthma. May be the addition of conventional physiotherapy to both experimental groups showed improvement in pre to post-test which is not included in the previous studies.

When compared between these groups, Buteyko method showed 
statistically significant improvement when compared to Nadi shuddhi Pranayama method with $\mathrm{p}$ value of 0.03 in $\mathrm{FEV}_{1}, 0.04$ in $\mathrm{FVC}$ and 0.03 in $\mathrm{FEV}_{1} / \mathrm{FVC} \%$. The significant change between the groups may be due to the breath holding exercises in the Buteyko technique which improves the gaseous exchange and maintains the $\mathrm{CO}_{2}$ and $\mathrm{O}_{2}$ levels which is not present in pranayama.

Based on the analysis, the present study found that 4 weeks of Buteyko breathing technique and Nadi shuddhi pranayama found statistically significant when compared pre to post test, but when compared between the groups Buteyko breathing group showed statistically significant improvement when compared to Pranayama group on improvement of pulmonary function in subjects with asthma.

\section{Limitations}

- The sample size studied was small.

- The frequency of the treatment sessions is less.

- The study did not include long term follow-up.

\section{Recommendations}

- Sample size can be increased with inclusion of a greater number of subjects to generalize the effects of these techniques in larger population.

- Further studies can be done to check the effects of these techniques on other conditions.

- Further studies can be done in child and adolescence asthma.

\section{CONCLUSION}

The results had shown that both Group-A (Buteyko Breathing Group) and Group-B (Pranayama Group) who received four weeks of therapy has improved significantly on pre and post-test values within the groups but when compared between these groups statistical significance is noted in Group-A. So, study concludes that there is significant difference between Group-A and Group-B in improving pulmonary function in subjects with Asthma.

Acknowledgement: None

Conflict of Interest: None

Source of Funding: None

Ethical Approval: Approved

\section{REFRENCES}

1. Behera D, Sehgal IS. Bronchial asthma-Issues for the developing world. Indian $\mathbf{J}$ Med Res. 2015;141(4):380-382. doi:10.4103/0971-5916.159237.

2. Asthma: National Institute for Health and Clinical Excellence (NICE) guideline DRAFT (January 2015).

3. Global Strategy for Asthma Management and Prevention (GINA) guidelines, 2015.

4. Asthma Care Quick Reference, Diagnosing and Managing Asthma, Guidelines from the National Asthma Education and Prevention Program, NIH Publication No. 12-5075 OP June 2002, Rev September 2012.

5. Holloway E and Ram FSF. Breathing exercises for asthma. Cochrane Database Syst Rev 2004; (1): CD001277.

6. Breathing Exercises and/or Retraining Techniques in the Treatment of Asthma: Comparative Effectiveness, AHRQ Publication No. 12-EHC092-EF September 2012.

7. Hondras MA, Linde K, Jones Ap. Manual therapy for asthma. Cochrane database Syst Rev 2011.

8. British guideline on the management of asthma. A national clinical Guideline, 2015.

9. Dr Alan Ruth. Behavioural medicine practitioner in private practice. The Buteyko breathing technique in effective asthma management.

10. Rosalba Courtney, DO. Strengths, Weaknesses, and possibilities of the Buteyko Breathing Method. Biofeedback Volume 36, Issue 2, pp. 59-63.

11. Senthil Kumar K, Jeneth Berlin Raj T, Prema Sembulingam and Tripathi PC. Consolidate effect of vibhagha pranayama, nadishuddi pranayama, savithiri pranayama and kapalabhati pranayama on the pulmonary functional status of young healthy male subjects. Volume 2 Issue 3 Int J Med Res Health Sci.2013;2(3):350-356. 
12. Sud Sushant Sud Khyati S. Effect of pranayama on pulmonary functions - an overview. International Ayurvedic Medical Journal ISSN: 23205091.

13. Teresa To, Sanja Stanojevic, Ginette Moores, Andrea S Gershon, Eric D Bateman, Alvaro A Cruzand Louis-Philippe Boulet. Global asthma prevalence in adults: findings from the cross-sectional world health survey. To et al. BMC Public Health 2012, 12:204.

14. Harold Kim, Jorge Mazza. Asthma. Kim and Mazza Allergy, Asthma \& Clinical Immunology 2011, 7(Suppl 1): S2.

15. Gauri Mayank Afle and Sumeeta Khaund Grover. To study the effectiveness of Buteyko breathing technique versus diaphragmatic breathing in asthmatics. Int $\mathbf{J}$ Physiother. Vol 1(3), 116-119, August (2014) ISSN: 2348-8336.

16. Giselle Mae C. Villareal Brian Paolo U. Villazor, Ailleen M. Villegas, Pio Sebastian N. Visaya, Mylene E. Vista*, Crestita B. Tan, and Charles Edward G. Florendo. Effect of Buteyko Method on Asthma Control and Quality of Life of Filipino Adults with Bronchial Asthma. JMHM Vol 2 Issue 12014.

17. Narwal Ravinder, Bhaduri S.N., Misra Aji. A study of effects of Buteyko breathing technique on asthmatic patients. Indian Journal of Physiotherapy and Occupational Therapy-An International Journal Year: 2012, Volume: 6, Issue: 4.

18. Zahra Mohamed Hassan, Nermine Mounir Riad, Fatma Hassan Ahmed. Effect of Buteyko breathing technique on patients with bronchial asthma. Egyptian Journal of Chest Diseases and Tuberculosis (2012) 61, 235-241.

19. Narendra gupta, Amit kumar, H.S.Joshi, Devendra kumar sharma . Effect of Yoga on Spirometric Valuein Bronchial Asthma Patients. Volume-4, Issue-7, July-2015. ISSN No 2277-8160.

20. Vungarala Satyanand, Gali Prakash Vignan Kumar, Namburi Bhargav Ram, Dhivya Mohanan, Shaik Ahamad Basha and Bingi Pavani Kumari. Study effect of two breathing techniques on pulmonary function in asthma. International Journal of Biomedical Research ISSN: 0976-9633 (Online) 10.7439/ijbr IJBRFA Volume-4, Issue-7, July-2015.ISSN No 2277-
8160Volume-4, Issue-7, July-2015. ISSN No 2277-8160 Volume.

21. Tanu Aggarwal, Anshu Khatri, Salman Shafi Siddiqui, Syed Neyaz Hasan, Deepankar Singh, Megha Kulshreshtha, Sudha Agarwal. Pranayama Has Additive Beneficial Effects Along with Medication in Bronchial Asthma Patients. J. Phys. Pharm. Adv.. 2013; 3(12): 292-297.

22. Savita Singh, Ritu Soni, K. P. Singh and O.P.Tandon. Effect of yoga practices on pulmonary function tests including transfer factor of lung for carbon monoxide (tlco) in asthma patients. Indian J Physiol Pharmacol 2012; 56(1): 63-68.

23. Madan, D., Singal, P., Kaur, H. Spirometric Evaluation of Pulmonary Function Tests in Bronchial Asthma Patients. Journal of Exercise Science and Physiotherapy, Vol. 6, No. 2: 106-111, 2010.

24. Khaleel Nagarchi, Saif Ahmed, Shaik Hussain Saheb. Study of Pulmonary Function Test in Asthma Patients. J. Pharm. Sci. \& Res. Vol. 7(1), 2015, 37-39.

25. Marjolein L.J. Bruurs, Lianne J. van der Giessen, Heleen Moed. The effectiveness of physiotherapy in patients with asthma: A systematic review of the literature. Respiratory Medicine (2013) 107, 483e494.

26. Ernesto Akio Taketomi, Gesmar Rodrigues da Silva Segundo, Sheila Mara Gonçalves Marra. Physiotherapy in asthma: Effects on pulmonary function and immune parameters. Fit Perf J, Rio de Janeiro, 4, 2, 98, Mar/Apr 2005.

27. Berlowitz D, Denehy L,Johns DP, Bish RM and Walters EH. The Buteyko asthma breathing technique. Med J Aust 1995; 162: 53.

28. Bruton A and Lewith GT. The Buteyko breathing technique for asthma: A review. Complementary Ther Med 2005; 13:41-46.

29. Singh V, Wisniewski A, Britton $J$ and Tattersfield A. Effect of yoga breathing exercises (pranayama) on airway reactivity in subjects with asthma. Lancet 1990; 335: 1381-1383.

30. Nagarathna $R$ and Nagendra HR. Yoga for asthma. Bangalore: Swami Vivekananda Yoga Prakashana, 1998:130-135.

31. Ritz T, Rosenfield D, Meuret AE, Bobb C and Steptoe A. Hyperventilation symptoms are linked to a lower perceived health in asthma patients. Ann Behav Med 2008; 35(1):97-104. 
G Swathi et.al. Effectiveness of Buteyko breathing technique versus Nadi shuddhi Pranayama to improve pulmonary function in subjects with Bronchial Asthma

32. Vedanthan PK, Kesavalu LN, Murthy CK, et al. Clinical study of yoga techniques in university students with asthma: a controlled study. Allergy Asthma Proc 1998; 19: 3-9.

33. Nagarathna $R$ and Nagendra HR .Yoga for bronchial asthma: A controlled study. BMJ 1985; 291: 1077-1079.

34. Cooper S, Oborne J, Newton S, et al. Effect of two breathing exercises (Buteyko and pranayama) in asthma: a randomized controlled trial. Thorax 2003; 58: 674-679.

How to cite this article: G Swathi, T Sunil Kumar, N Raghunadh et.al. Effectiveness of Buteyko breathing technique versus Nadi Shuddhi Pranayama to improve pulmonary function in subjects with bronchial asthma. International Journal of Science \& Healthcare Research. 2021; 6(4): 124-135. DOI: https://doi.org/10.52403/ijshr.20211019 